\title{
GRAFOS NA LEITURA DE AD
}

\section{MARIANA GARCIA DE CASTRO ALVES ${ }^{1}$}

Universidade Estadual de Campinas - R. Sérgio Buarque de Holanda, 571

Cidade Universitária, Campinas, SP, 13083-859

marianalagarcia@gmail.com

\begin{abstract}
Resumo. Busca-se uma reflexão sobre a leitura de grafos em redes digitais. O objetivo é compreender os efeitos de sentido produzidos pelo grafo enquanto forma material de arquivos contemporâneos. Como ferramenta, o grafo supera as capacidades individuais de memória. Assim, representa subjetividades historicamente constituídas, numa perspectiva externalista. Esse tipo de arquivo tem sido fonte para diversas áreas como antropologia, comunicação, marketing etc. Ao considerar tecnologia, ideologia e inconsciente, buscamos refletir criticamente sobre a leitura de grafos, numa relação de entremeio, metafórica, entre a teoria ator-rede (ANT), de Bruno Latour, e a análise automática de discurso (AAD), no entendimento de sentidos em circulação inscritos no modo de produção capitalista em seu estágio atual.
\end{abstract}

Palavras-chave: redes; grafos; arquivo; Análise Automática de Discurso; análise do discurso digital.

\begin{abstract}
This article seeks to understand the reading of graphs in digital networks. The objective is to think about the effects of sense produced by the graph as a material form of contemporary archives. As a tool, the graph exceeds the individual memory capacities. Thus, it represents historical subjectivities, from an externalist perspective. This type of archive has been source for several areas such as anthropology, communication, marketing, etc. Considering technology, ideology and unconscious, we seek to understand the reading of graphs critically, in a metaphorical relationship between Bruno Latour's actor-network theory (ANT) and the automatic discourse analysis, to understand the circulating meanings inscribed in the capitalist mode of production at its present stage.
\end{abstract}

Keywords: networks; graphs; archive; Automatic Discourse Analysis; digital discourse analysis.

\section{Introdução}

Este trabalho busca apresentar reflexões sobre a leitura de grafos, a partir da análise de discurso (AD) de filiação francesa. O objetivo principal é compreender os efeitos dessas redes na circulação de sentidos na atualidade.

\footnotetext{
${ }^{1}$ Doutoranda em Linguística na Unicamp.
} 
Para pensar tal arquivo na contemporaneidade, primeiramente, exporemos características de um programa (Gephi) que utilizamos para elaborar um grafo. Depois, retomaremos os grafos propostos na AAD-69, por Pêcheux e seu grupo, de modo a compará-los, em suas diferenças e similitudes, com aquele grafo por nós produzido. Após isso, com a finalidade de dar consequência às relações de entremeio ${ }^{2}$ nas quais a $\mathrm{AD}$ se inscreve, iremos nos avizinhar da teoria ator-rede, de Bruno Latour, bastante difundida em trabalhos com redes. Sopesaremos alguns de seus pressupostos e, com relação à ideia de não interação entre os agentes, isto é, de identificação dos atores no grafo, situaremos tal efeito dentro das discussões da AD. Assim, ao vislumbrar o engendramento de uma nova maquinaria de identificações, apontaremos possíveis efeitos de circulação do digital na atualidade e desafios colocados à leitura de grafos para os estudos de linguagem.

\section{A questão}

Um dos pilares do texto de 1981 "Ler o arquivo hoje", de Michel Pêcheux (2010, p. 49-59), é o de que o arquivo não seja transparente. O autor indica que os materiais disponíveis sobre determinado tema não teriam sentidos unívocos. Como em outros trabalhos, Pêcheux abre a leitura para a plurivocidade, para a polissemia, para o fato de que o sentido sempre pode ser outro. Ao lidar com a problemática histórica da "divisão social da interpretação" e das "clivagens subterrâneas" entre disciplinas, pela perspectiva do autor, o trabalho com a informática seria passível de se configurar como ameaça à plurivocidade. Assim, a informática arriscaria restringir a leitura "interpretativa", numa "normalização asséptica" (PÊCHEUX, 2010, p. 55) do arquivo. Atento às contradições do processo histórico, Pêcheux aponta, então, a necessidade de empreender uma "luta com o arquivo textual" (PECCHEUX, 2010, p. 59) em um trabalho do pensamento "em combate com sua própria memória" (PÊCHEUX, 2010, p. 59). ${ }^{3}$

Quase quarenta anos após a escrita desse texto, a leitura das formas do digital está constantemente presente em quase todas as ações do cotidiano: as pessoas informam-se, movimentam-se, fazem suas escolhas e expressam seus desejos com gestos de interpretação relativos a construtos informáticos. A utilização do computador se espraiou por todas as áreas científicas - inclusive pelas ciências humanas - e a maquinaria tecnológica de conexão em rede chegou às casas, como parte dos utensílios domésticos, e aos bolsos dos transeuntes da urbe, constantemente conectada. As inquietações de

\footnotetext{
${ }^{2} \mathrm{O}$ entremeio diferencia-se da interdisciplinaridade por não visar hierarquias e aplicações de uma disciplina a outra. Segundo Orlandi, o entremeio deve recair mais sobre o processo de significação e dos procedimentos (ORLANDI, 2012, p. 11). Isto é, a autora pensa a transversalidade das disciplinas conforme Pêcheux: "empréstimos que se usam como metáforas" (apud ORLANDI, 2012, p. 11). Para a autora: "Nem sobredeterminação, nem instrumentalização, nem aplicação. Uma relação metafórica, ressignificação, como a que se dá quando se toma discursivamente a não transparência do sujeito, a não transparência da língua, a não transparência da história. E não são tampouco empréstimos, digamos empíricos, são metáforas" (ORLANDI, 2012, p. 11).

${ }^{3}$ A ideia de "luta" e "combate" do arquivo consigo mesmo vai, de certo modo, ao encontro de Derrida que, embora tenha posicionamento teórico diverso, considera o arquivo constituído pelo paradoxal. Conforme o autor, "o arquivo trabalha sempre a priori contra si mesmo" (DERRIDA, 2001, p. 23). A "pulsão de arquivo" congregaria "sob a forma de uma pulsão de destruição, a pulsão mesma de conservação" (DERRIDA, 2001, p. 32).
} 
Pêcheux permanecem, pois o avanço que transformou o cotidiano de leitores em suas decisões práticas e ideológicas por meios tecnológicos reclama ainda mais por sentidos.

Neste artigo, apresentaremos a leitura de grafos como um aspecto dessa questão que, a nosso ver, tem demandado interpretação dos estudos de linguagem. O grafo é uma figura que representa, na matemática, um conjunto de elementos formados por vértices (nós) e arestas.

Entre as ferramentas de visualização de dados na era de $b i g ~ d a t a^{4}$, os grafos têm sido usados, por exemplo, como forma de leitura do comportamento nas redes sociais. Nesse campo, chamado de "humanidades digitais", trabalham profissionais de áreas como marketing, antropologia, comunicação, computação e outros. Com o desenvolvimento de algoritmos, é possível tornar legível a enormidade de registros de preferências e comportamentos na rede, algo impensável de ser feito individualmente. No Brasil, entre os laboratórios que têm trabalhado com softwares de mineração de dados para análise de redes sociais, destacam-se o Laboratório de Estudos sobre Imagem e Cibercultura (Labic) da Universidade Federal do Espírito Santo (Ufes) e o MidiaLab da Unversidade Federal do Rio de Janeiro (UFRJ), com expressiva produção com esse tipo de análise. ${ }^{5}$ Pela abrangência e pelas perspectivas abertas por essa área, podemos dizer que o grafo é uma das formas pela qual o mundo tem sido cada vez mais lido.

Embora a pesquisa com dados seja feita em institutos de pesquisa, atualmente, Twitter, Facebook e softwares para extração e coleta de dados são fontes acessíveis para quem tenha um computador e internet - e não apenas para o cientista social (BOYD; CRAWFORD, 2012, p. 664). Ou seja, a possibilidade de download de programas livres e de execução de leituras automáticas não está mais restrita ao especialista que se encontra no topo da divisão social da interpretação. É possível encontrar divulgação de outros tipos de mapas sobre assuntos diversos - como combinações de queijos com vinhos (ORENSTEIN, 2017) ou estilos de música (FÁBIO, 2016) - em sites populares como o do Nexo Jornal. Assim, de volta a Pêcheux, constata-se que, hoje, os "pobres" já não apenas "se interessam" pelas ciências do tratamento dos textos, conforme previa em "Ler o arquivo hoje" (PÊCHEUX, 2010), mas já as fazem circular como objetos ideológicos, na medida em que os dados (no caso, os apresentados por grafos) são vistos como evidentes ao sujeito. E aí, o big data aparece como prática empírica de "fatos" quando seria também uma prática de "interpretação" (BOYD; CRAWFORD, 2012, p. 667). ${ }^{6}$

Assim, um dos desafios da AD hoje seria, conforme Pêcheux, "saber fazer valer, face os riscos redutores do trabalho com a informática - e, logo, também nele - os interesses históricos, políticos e culturais levados pelas práticas de leitura de arquivo" (PÊCHEUX, 2010, p. 59). Dito de outro modo, seria desejável compreender os gestos de

\footnotetext{
${ }^{4}$ Em meio a um enorme volume de dados gerados constantemente - todos os nossos passos são registrados, desde as compras com cartão de crédito até nossos trajetos via celular - diversas ferramentas tornam essas informações legíveis para alguma finalidade. Propagandas direcionadas a públicos específicos ou campanhas de programas públicos de saúde com focos a populações determinadas ilustram algumas aplicações dessas tecnologias, dentro da era do big data.

${ }^{5} \mathrm{Na}$ página institucional de cada laboratório é possível encontrar a produção de cada um. No site do Labic/Ufes, estão elencadas também as repercussões na mídia de algumas pesquisas.

${ }^{6}$ Um estudo sobre big data e suas relações ideológicas, numa discussão com os primeiros textos de Pêcheux, ainda sob o pseudônimo de Thomas Herbert, pode ser encontrado em ALVES, 2016.
} 
leitura feitos pela informática para que pudéssemos entender se e onde esse trabalho resultaria em restrição de sentidos.

Importante notar que, em "Ler o arquivo hoje", Pêcheux sinaliza, como tarefa adicional, a realização de um trabalho informático. Mais que realizar análises do discurso sobre tecnologia, o autor considera necessário "também construir procedimentos algoritmos informatizados, traduzindo, tão fielmente quanto possível, a pluralidade dos gestos de leitura que possam ser marcados e reconhecidos no espaço polêmico das leituras de arquivo" (PÊCHEUX, 2010, p. 59). Juntando as tecnologias acessíveis e o trabalho com algoritmos já existentes na produção dessas leituras, apresentamos a seguir brevemente um grafo por nós construído para início dessa reflexão.

\section{Grafo de leitura}

Elaboramos um grafo no programa livre Gephi, a partir da leitura da obra "A língua inatingível. O discurso na história da linguística", de Gadet e Pêcheux (2004). A ideia inicial foi traçar um horizonte de retrospecção no sentido dado por Sylvain Auroux - isto é, um conjunto de conhecimentos anteriores à produção do conhecimento (AUROUX, 2008, p. 141). Queríamos verificar as relações feitas entre acontecimentos, autores, publicações e ideias na história da linguística apresentada na obra. ${ }^{7}$

Inserimos manualmente 624 nós - que foram os termos selecionados - e 917 arestas - que foram as ligações que, a partir de nossa interpretação do texto, estabelecemos entre esses termos. Assim, não contamos com programa de coleta de dados de línguas naturais.

Após essa inserção não automática no "laboratório de dados" do programa, aplicamos o algoritmo "Force atlas", que permitiu que o grafo ficasse mais legível na medida em que aproximou os nós mais conectados. Ainda aplicamos outro algoritmo, agora relativo à centralidade dos nós. O chamado "Centralidade do autovetor" conta a quantidade de caminhos feita para se chegar a um determinado nó. Um termo que tem mais centralidade é aquele pelo qual passam muitos outros caminhos.

Ao verificar os resultados, pudemos perceber ligações inesperadas. Algo relevante em termos de pesquisa, pois, apesar de termos feito as ligações manualmente em banco de dados, surpreendemo-nos com os caminhos gerados. Assim, pelo trabalho informático, passamos a reconhecer o grafo como uma "externalidade cognitiva" (AUROUX, 2008, p. 125-126) tal como bibliotecas, dicionários e livros. Ao notar relações inusitadas, mesmo que fôssemos nós quem as tivéssemos gerado, percebemos que, como "externalidade", o grafo supera as capacidades individuais de memória, atestando sua materialidade como objeto externo e histórico.

De acordo com Paveau, a perspectiva da existência de uma cognição externa responde pelo posicionamento teórico segundo o qual a produção discursiva está

\footnotetext{
${ }^{7} \mathrm{O}$ trabalho realizado no âmbito da história das ideias linguísticas ainda é inédito, mas já foi submetido e aprovado por banca de qualificação de área, dentro do programa de doutorado em linguística do IEL/Unicamp. Sem prejuízo a uma futura publicação, resumimos aqui apenas sua parte técnica.
} 
intrinsecamente ligada às ferramentas tecnológicas (PAVEAU, 2015, p. 3). Desse modo, a noção tradicional de suporte (a escrita sobre a pedra, papel e o digital) seria descartada, pois não haveria uma separação entre as ordens do material e outra da linguagem, mas apenas a ordem "tecnodiscursiva" (PAVEAU, 2015, p. 4).

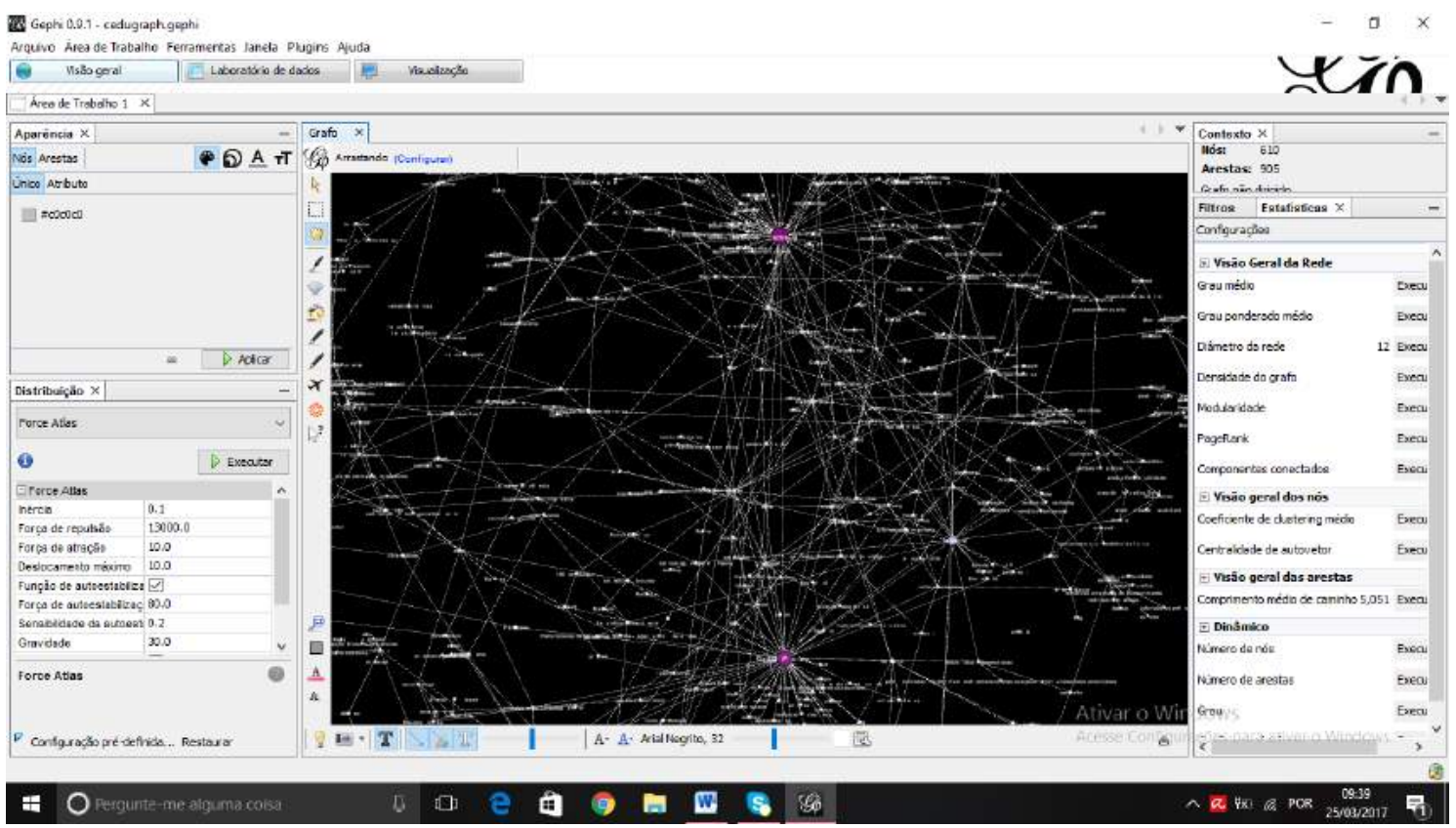

Fig. 1: Grafo (elaboração própria) encontra-se disponível em: https://marianalagarcia.wixsite.com/adigital. Acesso em 18. jul. 2017.

Nesse sentido, dizer que o grafo representaria "nossa" interpretação seria reduzir o problema. Ao considerar a posição externalista de Auroux (AUROUX, 2008, p. 125126) contrária à consideração corrente da cognição como algo interior ao indivíduo, a rede construída não se faz apenas como uma interpretação individual: para a $\mathrm{AD}$, faz-se, sobretudo, como uma interpretação de uma forma-sujeito ${ }^{8}$ historicamente constituída pelas condições de produção colocadas ${ }^{9}$.

\footnotetext{
8 Forma-sujeito, na $\mathrm{AD}$, refere-se não a um indivíduo particular, mas ao sujeito do discurso constitutivamente "colocado como autor de e responsável por seus atos" (PÊCHEUX, 2009, p. 198) pela interpelação ideológica. A expressão foi introduzida por Althusser: "Todo indivíduo humano, isto é, social, só pode ser agente de uma prática se se revestir da forma de sujeito. A "forma-sujeito", de fato, é a forma de existência histórica de qualquer indivíduo, agente das práticas sociais" (ALTHUSSER apud PÊCHEUX, 2009 , p. 150, nota 14). Ao pensar em “agentes de práticas sociais”, entendemos ser possível dizer que essa forma-sujeito possa se referir não apenas a humanos, como definiu Althusser. Basta pensar nas conexões de rede sociais, por exemplo, expressas pelos grafos. Nomes próprios importam menos, muitas vezes, que disparos artificiais de bots (robôs) não-humanos, isto é, "formas subjetivadas maquinalmente" (MALINI, 2016, p. 10). Estes, assim como os humanos, tampouco marcam, mas são marcados por posições de interpretação ideológicas. "É o sujeito que pertence a uma perspectiva e não o contrário" (CASTRO, Viveiros de apud MALINI, 2016, p. 10). Zizek, embora proponha um retorno à Hegel frente ao "novo materialismo" de Latour, aponta que o capital também é sujeito: "O sujeito não vem primeiro: é um sujeitoque-devém-predicado, uma tela passiva que afirma a si mesmo como um primeiro princípio, ou seja algo postulado que postula retroativamente seus supostos. Neste sentido: para Marx o capital é um sujeito: o capital é dinheiro que devém sujeito, dinheiro que não apenas faz a mediação, de forma que todo o movimento de intercâmbio de mercadorias devém auto-movimento do capital. O paradoxal é que Hegel não foi capaz de ver essa dimensão "hegeliana" da emergente ordem capitalista" (ZIZEK, 2017, p. 6).

9 Para a AD, "condições de produção" não são determinações do "contexto". Para escapar de armadilhas psicossociológicas em que os sujeitos são fontes das "circunstâncias", vale lembrar que Courtine (2009, p.
} 
Compreender como se constituem essas leituras baseadas na informática e de que maneira os sentidos são reduzidos, direcionados ou apagados nos grafos é nosso objetivo aqui. A fim de inserir a discussão no campo da $\mathrm{AD}$, façamos uma digressão à $\mathrm{AAD}-69$ (análise automática de discurso) para que entendamos como os grafos funcionavam como objeto de interpretação teórica de então.

\section{Grafos na AAD}

Como em toda leitura, se queremos refletir sobre um objeto que se apresenta de determinado modo nos dias atuais, temos de recorrer a trabalhos anteriores, por uma questão de localização teórica. Assim, a seguir, destacamos comparações entre os grafos da análise automática de discurso (AAD) e aqueles com os quais temos trabalhado. ${ }^{10}$

O dispositivo da AAD inscreve-se no campo do estruturalismo dos anos 1960, que buscava compreender o que seria ler, escutar e falar. Sob as batutas de Marx, Freud e Saussure (e também de Nietzsche, conforme PÊCHEUX et al., 2010, p. 252), a disputa era contra as noções de leitura dominantes de então: a) a de que a leitura dependia da subjetividade "interpretativa" sem limites do leitor (PÊCHEUX et al., 2010, p. 251); b) a das relativas à "análise de conteúdo" e c) a do "projeto de tratar os textos como populações de palavras" (PÊCHEUX et al., 2010, p. 252). O plano era analisar o "discurso inconsciente" das ideologias (PÊCHEUX et al., 2010, p. 252) e a linguística era o meio científico de afastar essas leituras dominantes supracitadas.

Com essa ideia a embasar seus procedimentos, a AAD-69 era dividida em três fases: a primeira, de construção dos corpora por meio de análise sócio-histórica (ou seja, da escolha dos corpora); a segunda, de uma análise sintática das superfícies dos textos, de modo a isolar os enunciados e também as relações entre eles e, por último, a terceira, de aplicação de procedimentos automáticos. A automação era vista como necessária na medida em que seria capaz de eliminar as "evidências subjetivas" do processo de leitura (PÊCHEUX et al., 2010, p. 254).

Os grafos eram, desse modo, formas de representação de enunciados que marcavam bases para a compreensão de trajetos discursivos. Sinteticamente, primeiro eram extraídas "sequências discursivas autônomas" (SDA), maiores que uma frase, podendo ser do tamanho de um parágrafo. Era feita a análise sintática das SDA a partir da qual eram produzidos manualmente os grafos. Nestes, os nós eram os enunciados (proposições que eram postas em oito categorias morfossintáticas) e as arestas eram conectores (de determinação, subordinação, coordenação) entre essas preposições. Formavam-se, assim, relações binárias (RB) - enunciado', conector, enunciado" - sendo que cada RB era uma ligação entre dois enunciados elementares (FUCHS; PÊCHEUX,

57) considera a noção de homogeneidade das condições de produção, presente na AAD-69, um obstáculo. O motivo é que todo discurso se insere em um processo discursivo que o determina a partir de elementos pré-construídos. Esse "sempre já aí", instaurado por Paul Henry, é produzido em discursos anteriores e independentes e se reproduz sob a determinação do seu interdiscurso. Ao construir um corpus tomando como homogênea a condição de produção, em plano sincrônico, corre-se o risco de definir condição de produção como situação de comunicação, pelo motivo de produzir um esquecimento do interdiscurso.

${ }^{10}$ Grafos estão disponíveis em https://marianalagarcia.wixsite.com/adigital. 
2010, nota 61, p. 212). Cada RB tornava-se, então, uma unidade de comparação entre os corpora. Essa comparação era feita por meio de um peso positivo (1) dado à identidade e nulo $(0)$ dado à diferença "dos conteúdos literais dos dois enunciados do par" (FUCHS; PÊCHEUX, 2010, p. 214). Assim, por meio de tratamento informático, com algoritmo, enunciados próximos eram transformados em quádruplos, cadeias e "domínios semânticos", sucessivamente. ${ }^{11}$

Após esse processo - que corresponde à segmentação em SDA, análise sintática e análise automática - o pesquisador de análise do discurso poderia iniciar seu verdadeiro trabalho (PÊCHEUX et al., 2010, p. 266).

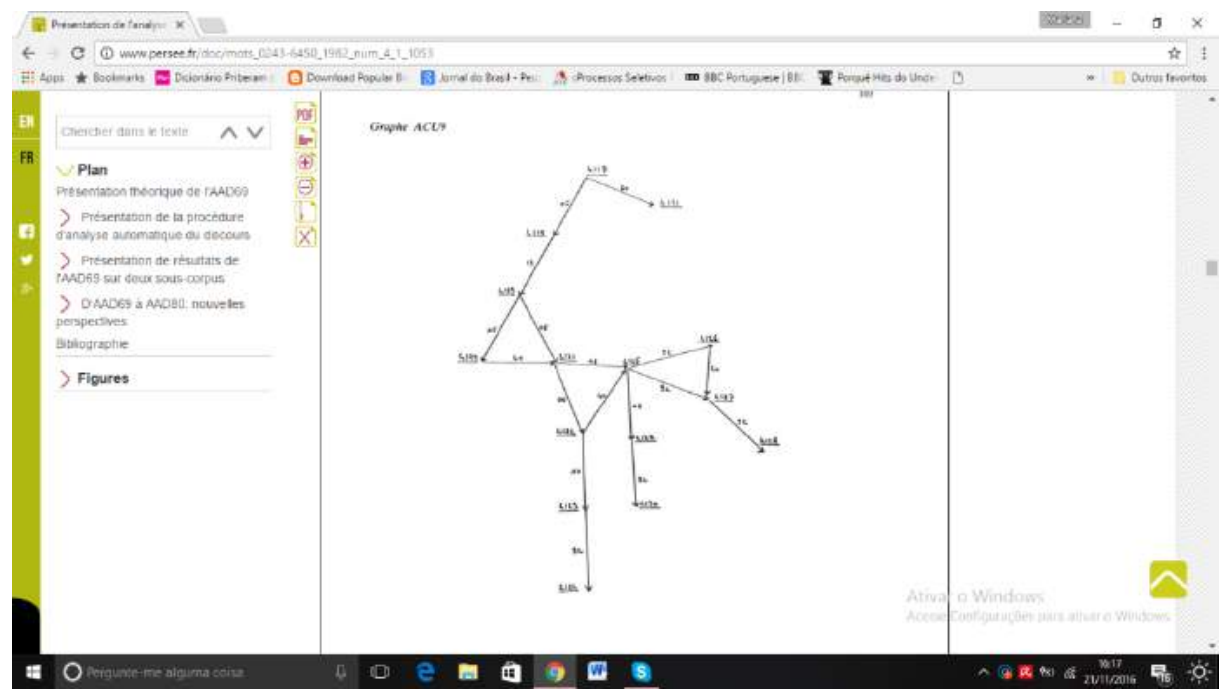

Fig. 2: Grafo da AAD-69 (PÊCHEUX et al., 1982). Disponivel em: http://www.persee.fr/doc/mots 02436450_1982_num_4_1_1053. Acesso em 18. jul. 2017.

Em 1975, Fuchs e Pêcheux propõem uma "atualização" dessa AAD-69 e ainda apontam perspectivas que pudessem reduzir a distância "que separa a análise de discurso da teoria do discurso" (FUCHS; PÊCHEUX, 2010, p. 161), ou seja, que pudessem superar o atraso dos "procedimentos práticos de tratamento dos textos em comparação com o nível atingido nas discussões" sobre as relações entre materialismo histórico, linguística e teoria do discurso (FUCHS; PÊCHEUX, 2010, p. 161).

Em 1981, Pêcheux e, em 1982, o autor junto com outros da sua equipe - Léon, Marandin e Bonnafous - fazem nova autocrítica desses procedimentos. Basicamente, os processos efetuados teriam resultado em uma máquina de produzir identificações, que desprezava as ambiguidades, a polissemia das línguas naturais, dando sentidos unívocos. Isso teria feito surgir uma nova teologia, a teologia da estrutura, para auxiliar no conhecimento do discurso como uma prótese de leitura, uma máquina de lavar textos.

\footnotetext{
${ }^{11}$ No caso da AAD-75, a inclusão e intersecção entre domínios eram chamadas de relações paradigmáticas. Já o andamento do processo discursivo do corpus eram as relações sintagmáticas, as quais permitiriam traçar o grafo do processo discursivo (FUCHS; PECHEUX, 2010, p. 218). Depois da análise distinta de um corpus A e de um corpus $\mathrm{B}$, era feita a compactagem, aglomerando os domínios de A e B. As modalidades de comparação das RB, no inter ou intradiscurso, ensejariam, segundo texto de 1975, a problemática ligada ao "discurso do outro no interior do mesmo discurso" (FUCHS; PÊCHEUX, 2010, p. 221).
} 
Entre as autocríticas, estão afirmações que aparentemente rompem com qualquer projeto de análise automática: "os procedimentos da AAD 69 ficam bem mais próximos do que eu poderia supor na época das evidências empírico-lógicas da leitura" (PÊCHEUX, 2014, p. 281) e:

nós temos daqui em diante os meios de sustentar argumentativamente, sobre o terreno da informática, a tese segundo a qual as ambiguidades, metáforas e deslizamentos próprios às línguas naturais são propriedades incontornáveis do campo da análise do discurso, que se diferencia por essa razão mesma de toda perspectiva estritamente informacional, documentária ou "intelectiva". Um corpus de arquivo textual não é um banco de dados. (PÊCHEUX, 2014, p. 280 -281)

Em resumo, a AAD-69 foi considerada uma máquina de produzir identidade, ou melhor, um procedimento que reduzia o discurso a tipologias (o discurso comunista, o socialista...). O problema era a decomposição em séries discursivas e sua redução a um modelo simplificador (PÊCHEUX et al., 2010, p. 278) como uma muleta de leitura e não como uma provocação à leitura.

Apesar de, por exemplo, em 1975, em "A propósito da análise automática do discurso: atualização e perspectivas", serem debatidas em detalhe as justificadas críticas feitas por outros à ADD-69 e, ao mesmo tempo, também ser empreendida sua autocrítica, em 1982 afirmava-se que a ideia subjacente ao projeto não deveria ser rejeitada in totum:

Contudo, a ideia de um algoritmo paradigmático de parafraseamento, a ideia de um levantamento de caminhos ligados ao fio do discurso não são invalidadas: elas podem efetivamente constituir um aspecto, interpretado de outro modo diferente, dos novos algoritmos. (PÊCHEUX et al., 2010, p. 255)

Dessa maneira, o reconhecimento dos defeitos da AAD tinha se tornado "condição para que a análise do discurso (pudesse então) continuar a seguir seu próprio caminho" (PÊCHEUX, 2014, p.282). Para colocar questões sobre o discurso digital hoje, partamos dessa esteira. Com a finalidade de retomar essas discussões a partir de perguntas atuais, comparemos, então, tal maquinaria com o grafo que elaboramos.

Nosso grafo não é um modo de visualização de uma representação da estrutura de superfície ou profunda do texto, como objetivava a AAD, e nem se enquadra no campo de processamento de linguagem natural (PLN). Embora não se refira à análise de sequências discursivas autônomas (SDA) tal qual o realizado pela $\mathrm{AAD}$, utiliza algoritmo que aproxima os elementos dispostos manualmente, assim como na AAD. Além de não ser sobre sequências discursivas - não procedemos a tratamento de enunciados, mas a ligações entre ideias, referências, datas, enfim, para usar a expressão utilizada por Latour et. al (2015), "atores em rede" -, outra diferença entre este grafo e o da AAD é que, em nosso grafo, as arestas não são direcionadas.

Enquanto, na $\mathrm{AAD}$, os conectores dão direção entre os enunciados nas $\mathrm{RB}$, em nosso grafo as arestas têm mão dupla. Em vez de uma leitura estruturada pelo encadeamento da língua representado pela arborescência da $\mathrm{AAD}$, nosso grafo leva a uma leitura não sobre a forma de árvore, mas sobre um tecido em rede. Tal apagamento do 
direcionamento das arestas suscita, de imediato, que se indaguem quais seriam os efeitos dessa leitura em rede.

Para pensar essa questão, vejamos três efeitos de substituição com os quais Fuchs e Pêcheux, em 1975, distinguem três tipos de relações entre as RB. As primeiras relações seriam aquelas em que o sentido não é transformado, em que pesem restrições ("Conservamos esta designação, ao menos a título de caso-limite, permanecendo circunspectos acerca do fundamento desta hipótese” (FUCHS; PECCHEUX, 2010, p. 238). Consistia no caso em que se mantinham as unidades lexicais como em: "por exemplo: "Os romanos decidiram destruir Cartago" --- $\rightarrow$ "A destruição de Cartago foi decidida pelos romanos"” (FUCHS; PÊCHEUX, 2010, p. 238). As segundas mudariam o sentido e seriam aquelas em que haveria mudança lexical. Essas substituições foram chamadas por Fuchs e Pêcheux de "orientadas" e tinham relação com transformações "incremenciais" de Harris, isto é, as que incrementam ou adicionam "informação", diferentemente das transformações parafrásticas (FUCHS; PÊCHEUX, 2010, p. 238).

Já as terceiras - essas seriam introduzidas por Fuchs e Pêcheux ao esquema de Harris - seriam as substituições não orientadas com mudanças lexicais. Entraria o problema da sinonímia, que não está nem no primeiro, nem no segundo caso: "No entanto, é nessa perspectiva que concebe a sinonímia como um apagamento da orientação (e não como uma extensão lexical da equivalência sintática), que nos parece fecundo orientar as pesquisas" (FUCHS; PÊCHEUX, 2010, p. 238).

Vemos assim que, na $\mathrm{AAD}$, as substituições são orientadas não apenas pelas flechas conectoras determinantes da ordem da ocorrência dos enunciados (primeiro um, depois o outro), mas também pelas relações de sentido expressas pelos três tipos de transformações acima descritos. Em outras palavras, coloca-se em pauta não apenas os caminhos possibilitados pelas cadeias, mas pelas relações de sentido entre os enunciados.

Ao pensar na AAD-69 como metáfora para nosso grafo e na terceira relação de transformação de enunciados proposta por Fuchs e Pêcheux, é possível dizer que a não orientação das arestas do nosso grafo implicaria não apenas a falta de trajetos predeterminados, mas também conferiria efeito de sinonímia entre os nós, apagando deslocamentos de sentido entre um vértice e outro. Ou seja, o não direcionamento das arestas do grafo poderia, a partir das pistas de Fuchs e Pêcheux, estabelecer uma relação entre os nós de sinonímia não orientada. Dito de outra forma, os termos dos nós seriam diferentes, porém não haveria efetivo "deslocamento" no passeio pela rede ${ }^{12}$.

Uma das consequências dessa percepção é a tendência ao mesmo na leitura do grafo. Por exemplo, quando dois nós com efeito de sentidos opostos entre si (nazista judeu) estão ligados por uma aresta, caso tenhamos alguma razão, a leitura tende a

\footnotetext{
${ }^{12}$ Tal reflexão nos leva a afirmar que, se o grafo da AAD-69 com suas arestas orientadas eram representação de um trajeto discursivo, seria impróprio pensar nos grafos em rede também como trajetos discursivos, pois trajetos suporiam caminhos orientados. Há diferenças que devem ser levadas em conta, de outro modo, corre-se o risco de "salada teórica", em que se retomam conceitos da AD (como sujeito, interdiscurso, memória, formação discursiva) "tentando domesticá-los em uma aproximação positivista em que eles deixem de ser corrosivos como são em relação à ciência. Aí se pode observar o afã "criativo" da análise do discurso que quer ser atual e que, na realidade, é um retorno da tentativa de silenciamento do que é o discurso como objeto específico, em uma relação consistente entre teoria/método/procedimentos analíticos e objeto, pensando o político, a ideologia" (ORLANDI, 2012, p. 29).
} 
circunscrevê-los a um mesmo contexto ou até posição, apagando as diferenças, num efeito de sinonímia com mudança lexical.

Se esse efeito de sentido ocorre, assim como assevera Pêcheux em "Análise de discurso e informática" (2014) sobre a AAD, poderíamos dizer que nosso grafo digital representa um esquema do homem prático, um modelo manipulável, uma representação utilizável. Uma estrutura, podendo ter aplicação pedagógica, reduzida à tradução parafrástica. $^{13}$

Mas, para que não nos fixemos nesse ponto de vista redutor das possibilidades do grafo, arriscando a imobilizar a pesquisa, passemos também a levar em consideração uma perspectiva não discursiva que, todavia, coloca questões para a AD.

\section{Cartografia do discurso}

Em "O todo é sempre menor que as partes: um teste digital acerca das mônadas de Gabriel Tarde" (2015), Latour et al. fazem uma defesa da teoria social de Tarde (18431904) a partir dos recursos de conhecimento digitais disponíveis atualmente. A tese é a de que, com tecnologias capazes de rastrear indivíduos através de suas conexões, é possível hoje provar empiricamente a posição de Tarde, para quem seria produtivo não distinguir o nível do indivíduo do nível da estrutura, mas considerar as relações "planas" da sobreposição de mônadas, ou seja, das redes.

Em vez de dois níveis (de saltos do micro para o macro, ou do macro para o micro), os dados deveriam ser tratados como sendo de apenas um nível. Isto é, em vez de dar relevância à busca das determinações individuais de cada formiga na construção de um formigueiro, por exemplo, o pesquisador deveria se abster dessa questão que, aliás, interessa apenas ao pesquisador e não à própria formiga, visto que esta não tem a visão de todo o ninho.

Trata-se, assim, de uma teoria de redes e perspectivas. A teoria ator-rede (cujo acrônimo do inglês ANT relaciona-se com formigas, diga-se de passagem) prevê que um ator seja definido por sua rede (LAW; HASSARD, 1999 apud LATOUR et al., 2015, p. 10), sendo que "essa rede não é um segundo nível adicionado a aquele nível do indivíduo, mas exatamente o mesmo nível posicionado diferentemente." (LAW, 2004 apud LATOUR et al., 2015, p. 10). Assim, haveria "mais complexidade nos elementos que nos agregados" (LATOUR et al., 2015, p. 9).

Atualmente, diversas plataformas, como a web 2.0, tornaram o princípio monadológico de Tarde passível de visualização. A pesquisa pelos perfis é o exemplo tomado pelos autores para expor a navegação nas redes como fonte de perspectiva sociológica alternativa. A ilustração consiste na busca do currículo de certo professor. Primeiramente, tem-se seu nome, depois a instituição de ensino com a qual tem vínculo, depois por onde passou, com que temas tem trabalhado etc. "Se continuarmos por meio da lista de atributos, a definição irá se expandir até que, paradoxalmente, irá diminuir a

\footnotetext{
${ }^{13}$ Orlandi refere-se à história para certificar "limites fluidos e cambiantes" entre "a "leitura parafrástica"
} (ou ad mentem auctoris) e a "leitura polissêmica" (ou livre interpretação)" (ORLANDI, 2008, p.47). 
uma instância cada vez mais e mais específica" (LATOUR et al., 2015, p. 9) de modo que, ao aplicar um "zoom out" e se perguntar "quem é esse nome", a resposta será: a rede. "O conjunto de atributos - a rede - agora pode ser entendido como um envelope - o ator - que encapsula seu conteúdo em uma notação abreviada" (LATOUR et al., 2015, p. 10).

Para Latour et al., as mônadas são reversíveis, ou seja, suas arestas não são orientadas. A circulação ou navegação é determinante na forma de apreensão dos dados. Além disso, não há diferença entre humanos e não humanos, nas conexões planas da rede. Se quiséssemos saber qual é a universidade a qual o professor está ligado, bastaria ir até essa outra lista e verificar, por exemplo, seus acadêmicos.

não há diferença real na busca de identidade de uma pessoa, de um lugar, de uma instituição, de um evento e assim por diante. Em todos os casos a operação empírica e cognitiva é a mesma. Ao circular de tal maneira do ator para a rede e de volta para o ator, nós não estamos mudando os níveis, mas simplesmente parando momentaneamente em um ponto, o ator, antes de passar para os atributos que o definem. (LATOUR et al., 2015, p. 10)

Interessa-nos aqui que, ao serem definidos por sua rede, os atores guardam entre si relações de identificação. Conforme se navega, passa-se de um atributo a outro e, assim, "cada um dos atributos usados a fim de definir a entidade é modificado em si, tornandose o atributo desta entidade" (LATOUR et al., 2015, p. 14). Desse modo, ao passear pelas conexões, a universidade em que dá aula o professor do exemplo acima seria, ela também, "ligeiramente diferente" (LATOUR et al., 2015, p. 14). ${ }^{14}$ Assim, a cada vez que a universidade é repetida, o é com variações. Sendo remetida a muitos outros atores, tornase o que cientistas sociais chamam de "instituição", atribuindo-lhe um nível mais alto. Latour et al., por outro lado, resistem a essa ideia ao argumentar não haver diferença entre indivíduos e grupos ou instituições, pelo fato de que, se o professor fosse mais citado que a universidade, ele seria a instituição.

Ao passo que a noção atomística é rejeitada, a interação como forma de articulação dos atores também o é.

Em 1-LS, pelo contrário, os agentes não podem ser considerados, falando rigorosamente, "interagir" com um outro: eles são um outro, ou melhor, eles possuem um outro, uma vez que cada item listado para definir uma única entidade pode também ser um item na lista que define outro agente (TARDE 1903; 1999 [1895]). (LATOUR et al., 2015, p. 14)

A interação entre agentes individuais é, assim, suplantada pela identificação entre atores da rede. A nosso ver, uma das qualidades dessa teoria é colocar atores humanos e não humanos em um mesmo plano ${ }^{15}$. Em nosso grafo, elaborado para trabalho de história

\footnotetext{
${ }^{14}$ Deleuze é citado para a compreensão desse efeito de diferença no mesmo: "Se estivermos certos, “imitação" para ele (Tarde) não é antes de tudo um fenômeno psicológico, mas a percepção de que as mônadas compartilham atributos modificados a cada partilha, cujo resultado é uma lista composta pelo "mesmo" item repetido com diferença (DELEUZE, 2005)" (LATOUR et al., 2015).

${ }^{15}$ Os autores ainda respondem às evidentes diferenças entre humanos e não humanos, ao reconhecer que somos equipados, inclusive com instrumentos, para conhecer a totalidade em que "acreditamos" viver. Para marcar essa diferença, propõem um ponto de vista intermediário (1,5 - LS).
} 
das ideias linguísticas, tal característica foi fundamental para fugir do esquema de linhas do tempo, baseadas em nomes e datas cronológicas. Sentidos não estão encaixotados em categorias. Com a rede, pudemos estabelecer ligações entre ideias, conceitos, acontecimentos históricos, autores, movimentos, publicações... Todos, de alguma forma, atores na história do discurso na linguística traçada por Gadet e Pêcheux.

A defesa da utilização indistinta entre atores humanos e não humanos nos parece razoável visto que, ao afastar um tipo de humanismo voluntarista, buscamos compreender os aspectos - humanos e não humanos - que concorrem para a constituição da forma sujeito no modo de produção em sua configuração atual ${ }^{16}$. Vemos razão na tomada de atores não humanos no mesmo plano dos atores humanos, principalmente em época de bots que disparam hashtags em disputas ideológicas na rede - com efeitos não apenas virtuais.

Todavia, embora colocar, em mesmo plano, nomes, datas e instituições não vá de encontro aos fundamentos da $\mathrm{AD}$ a nosso ver, é preciso pensar nos efeitos de sentido. Tomemos uma simples questão de leitura.

Embora a universidade esteja no mesmo plano do professor, quem tiver mais ligações será lido como o mais importante. Se muitos professores trabalham em uma só universidade, esta será mais repetida. O nó mais repetido ganha tamanho maior ou até cor mais destacada no programa, por meio de seus algoritmos. Desse modo, mesmo que humanos e não humanos estejam lado a lado, a hierarquia entre os agentes que Latour et $a l$. procuram amenizar ainda permanece como efeito de leitura no grafo. Qualquer seja a "instituição" (o professor ou a universidade), ao final, a leitura da sobreposição confusa da enormidade de dados ainda demanda noções de seleção, hierarquia, ou melhor, de valor.

Entretanto, ao contrário do valor tomado no seu sentido negativo, como em Saussure, em que um signo é o que os outros não são, aqui um agente é o que os outros o fazem ser: "Ser parte de uma totalidade [...] para qualquer mônada é emprestar parte de si mesmo a outras mônadas sem que nenhuma delas perca suas múltiplas identidades" (LATOUR et al., 2015, p. 20).

Fica posto que o efeito do grafo seja, então, de redução das diferenças entre os termos, embora, registre-se, a tensão da rede só ocorra por suas diferenças. A busca é de identificação entre os nós. Imaginar causalidades nas ligações, o principal ato de leitura. Somos movidos pelo afeto, pelas ideias e nomes que nos chamam, pela memória, com o que nos identificamos. O pesquisador no trabalho de análise do grafo, por sua vez, tenta estabelecer variáveis que, simplificadamente, capturem "a riqueza de associações", buscando o que há em comum entre elas.

Retomando Fuchs e Pêcheux, pode-se dizer, assim, que as relações dominantes estabelecidas no grafo são de sinonímia, onde cada ator é substituído por outro, em transformações que comportam mudanças lexicais não orientadas, ou seja, mudam-se os termos, mas não os sentidos. Joga-se com o que cada nó empresta ou toma emprestado de outro em meio a suas "ligeiras" diferenças.

\footnotetext{
${ }^{16}$ Conferir nota 7.
} 
É ainda por essa lógica de indistinção que os autores creditam à falta de informação a insistência em dois níveis. Ou seja, para eles, a grande quantidade de dados hoje disponível não supre totalmente, mas permite que essas identidades sejam relacionadas sem perda. Para Latour, seria "até possível argumentar que a própria noção de "interação" como um encontro ocasional entre agentes separados é uma consequência de informações limitadas sobre os atributos que definem os indivíduos" (LATOUR, 2010, apud LATOUR et al., 2015, p. 14).

A ideia, no fundo, é que se tivéssemos mais informação, os problemas seriam mais facilmente resolvidos. Essa tese nos parece problemática não pelos avanços científicos ainda muito recentes ${ }^{17}$, mas porque desconsidera a língua e, ao contrário do que diz recusar, acaba por corroborar pressupostos como o da interação entre agentes. Seria como se o acesso ao grande volume de dados pudesse fazer os indivíduos compreenderem suas conexões com a rede, com o outro.

Não há quantidade de informação capaz de liquidar com a questão de que a interpretação seja uma injunção, isto é, "diante de qualquer objeto simbólico, somos instados a dar sentido, a significar" (ORLANDI, 1996, p. 89). Ela está tanto presente na construção do grafo - por exemplo, nos comandos fornecidos para a definição dos termos que serão os nós - quanto na sua leitura, como no caso da hierarquia entre termos, e na própria legibilidade da sobreposição.

O apagamento da língua - tanto nessa observação de Latour quanto na forma visual do grafo cujas arestas não têm orientação - concorre para a ilusão de que a rede toca seu objeto sem mediação de linguagem. Conforme Herbert, poderíamos dizer que esse arquivo digital daria ensejo a uma forma ideológica empirista que esquece a relação metafórica entre o significante e o significado, ao remeter a "prova de realidade" ao objeto e não a essas relações (HERBERT, 1995, p. 73). A despeito de Latour et al. afirmarem não considerar que os dados reflitam a "vida real" (LATOUR et al., 2015, p.15), o ajuste da técnica ao real resta como efeito. Assim, a teoria ator-rede com sua exploração feita sobre "indivíduos", "grupos", "agentes" imersos em movimentos informacionais, carrega noções de leitura historicamente combatidas pela $\mathrm{AD}$, em especial as de análise de conteúdo (PÊCHEUX et al., 2010, p.252) que considera o sentido como informação do texto a ser decodificado em situação de comunicação.

Importante ressaltar que a forma dessa tecnologia de leitura - que, como estamos a afirmar, supõe redução das diferenças e indistinção entre os nós - não deve ser considerada em abstrato. É preciso observar não apenas como o sentido é constituído e formulado, mas também como circula. Alternativamente, poderíamos pensar que, a leitura do grafo possibilitaria interpretações outras justamente por não imobilizar os trajetos, por sua característica "reversível". Ou seja, nosso grafo não seria simplesmente uma "prótese de leitura" de um arquivo, mas outro texto. Ademais, a memória do leitor, suas "histórias de leituras" (ORLANDI, 2008, p. 41-46) também seriam capazes de imprimir novos sentidos à univocidade do grafo.

\footnotetext{
${ }^{17}$ Para Davidowitz, o big data substituirá outros métodos de captura de dados, mas crê que, por enquanto, "precisamos das formas tradicionais de obter dados. Ainda precisamos de mais algumas eleições, por exemplo, para desenvolver modelos de interpretação de informações e identificação de tendências de votos" (EXAME, 2017).
} 
Dessa maneira, vale lembrar que tanto para Fuchs e Pêcheux quanto para Latour et al., o trabalho do analista ocorre depois do procedimento informático. Portanto, a questão é de que maneira e sob quais condições esse arquivo digital será lido. Uma ilustração de como os arquivos digitais podem ser interpretados de diferentes modos é apontada por Malini (2016, p.5) ao criticar analistas de redes sociais que, para vender inserção de marcas no mercado, usam um modelo individualizante baseado na ideia de que os nós mais influentes na mídia valeriam mais que postagens de anônimos, posição contrária à qual o pesquisador trabalha.

Segundo Orlandi, "para que a língua faça sentido, é preciso que a história intervenha, pelo equívoco, pela opacidade, pela espessura material do significante" (ORLANDI, 2005, p. 47).

Portanto, somos levados a pensar, então que, ao considerar a língua, a história e o inconsciente, interessaria empreender gestos de leitura do grafo que tentassem romper a tendência de imobilização de sentidos aqui apontada pelo efeito de sinonímia não orientada, dando significado ao que seria empreender uma luta do arquivo consigo mesmo.

\section{Conclusões}

Ao tentar compreender uma discussão contemporânea a respeito de novas tecnologias de linguagem, fizemos relações metafóricas entre a teoria ator-rede e os resultados da AAD empreendida entre os anos 1960 e 1980.

Essas relações tornaram possível que pensássemos nos efeitos de sentido na leitura de grafos. Os efeitos de sinonímia não orientada da AAD e o de identificação do ator como sendo sua rede permitiram que observássemos o modo como a univocidade funciona nessa forma de arquivo digital.

Indicamos o apagamento da língua e a decorrente ideia de que o grafo representaria os fatos diretamente e não uma interpretação. Porém, apontamos também que, a partir de uma perspectiva externalista, ao superar as capacidades individuais de memória, o grafo não resultaria simplesmente da intencionalidade do programador, mas implicaria uma tecnologia própria dos tempos capaz de dar indícios de nossos gestos de leitura.

Como discurso técnico, a "ilusão" de ajuste ao "real" residiria nessa capacidade do programa de permitir visualizações de grande conjunto de dados. Essa aptidão, entretanto, viria a corroborar o mito da quantidade de informações como solução para o conhecimento e a interação comunicacional.

Para Orlandi, o conhecimento em seu funcionamento "pelas redes, pela informação imediata, pelo consumismo, pela quantidade, pela desconexão com o sistema produtivo" (ORLANDI, 2012, p. 25) seria um dos efeitos da mundialização como ideologia capitalista oferecida ao consumidor. Enquanto lugar de quantidade de informação e de rarefação da reflexão, o digital daria a ilusão de que a relação com o 
interdiscurso $^{18}$ não estaria em funcionamento, ou seja, o conhecimento se tornaria consumo e silenciaria o político.

Contradição entre o real da divisão e o imaginário da difusão e da rapidez de informação que dá, com frequência, origem ao que tenho chamado "o intelectual da internet", o conceito vira senso-comum, informação, o pesquisador vira usuário. Descompromete-se com a história, apaga a ideologia, enquanto esta se articula à própria língua. (ORLANDI, 2012, p. 25)

Em meio a tecnologias de linguagem que propiciam tais apagamentos, pensamos, a partir dessa análise, ser lícito dizer que leituras unívocas difundidas pela informática tenham um funcionamento próprio de memória metálica ${ }^{19}$ em que grassa a "variedade sem ruptura" (ORLANDI, 2010, p. 9).

Ao compreender os modos de circulação do digital dessa maneira, empreender uma leitura crítica dos construtos técnicos digitais que fazem parte das "coisas-a-saber" do "sujeito pragmático" (PÊCHEUX, 2008, p. 34) no século XXI faz-se possível e necessário.

Possível, pois, se "não há ritual sem falhas; enfraquecimento e brechas" (PÊCHEUX, 2009, p. 277), então certamente há lacunas para que as associações entre os nós do grafo sejam lidas criticamente. Ademais, se "uma palavra pela outra" é a "definição da metáfora, mas é também o ponto em que o ritual se estilhaça no lapso" (PÊCHEUX, 2009, p. 277), é possível que tal ponto de substituição também seja encontrado nas associações que ligam um termo a outro nos grafos.

Por fim, necessário, pois uma crítica dessas plataformas justifica-se não por um desvelamento de uma verdade escondida - na medida em que falamos de efeitos de sentido - mas por um avanço em direção à "justiça" (PÊCHEUX, 2009, p. 276) no que tange às possibilidades da polissemia, em um mundo barbarizado pelos valores unívocos e assépticos do capital.

\footnotetext{
18 Pêcheux propõe chamar de interdiscurso "'todo complexo com dominante" das formações discursivas, esclarecendo que também ele é submetido à lei de desigualdade-contradição-subordinação que, como dissemos, caracteriza o complexo das formações ideológicas” (PÊCHEUX, 2009, p. 149). Orlandi, nessa filiação, caracteriza o interdiscurso como "esse conjunto de enunciações já ditas e esquecidas e que são irrepresentáveis" (ORLANDI, 2006, p. 21- 22).

${ }^{19}$ A noção de memória metálica de Orlandi (2010) refere-se, em contraposição à memória histórica, àquela produzida por um construto técnico como televisão e computador: "Sua particularidade é ser horizontal (e não vertical, como a define Courtine), não havendo assim estratificação em seu processo, mas distribuição em série, na forma de adição, acúmulo: o que foi dito aqui e ali e mais além vai se juntando como se formasse uma rede de filiação e não apenas uma soma, como realmente é, em sua estrutura e funcionamento. Este é um efeito - uma simulação - produzido pela memória metálica, memória técnica. Quantidade e não historicidade. Produtividade na repetição, variedade sem ruptura. E o mito, justamente, desta forma de memória é o "quanto mais, melhor" (ORLANDI, 2010, p. 9).
} 


\section{Referências}

ALVES, Mariana G.C. Big data e as pegadas do monstro: o digital na leitura da Análise do Discurso. RUA [on-line, Especial - Cidade Conectada, p. 151-174], out. de 2016. Disponível em http://www.labeurb.unicamp.br/rual. Acesso em: 18. jul. 2017.

AUROUX, S. A questão da origem das línguas [seguido de A historicidade das ciências]. Campinas: RG, 2008.

BOYD, D.; CRAWFORD, K. Critical Questions for Big Data. Information, Communication \& Society, v. 15, n. 5, pp. 662-679, june 2012.

COURTINE, J-J.. Análise do discurso político:discurso comunista endereçado aos cristãos. São Carlos: EdUFSCar, 2009.

DERRIDA, J. Mal de arquivo: uma impressão freudiana. RJ: Relume Dumará, 2001.

EXAME. Só o Google sabe realmente tudo, diz estudioso de big data. Disponível em http://exame.abril.com.br/revista-exame/so-o-google-sabe-realmente-tudo-dizestudioso-de-big-data/. Acesso em 14.jul.2017

FÁBIO, A.C. Este mapa vai fazer você se encontrar entre 1.400 estilos musicais. Nexo Jornal, 29, mar. 2016. Disponível em https://www.nexojornal.com.br/expresso/2016/03/29/Este-mapa-vai-fazervoc\%C3\%AA-se-encontrar-entre-1.400-estilos-musicais. Acesso: 19.jul.2017.

FUCHS, C.; PÊCHEUX, M. A propósito da análise automática do discurso: atualização e perspectivas (1975). Em: GADET, F.; HAK, T. (Orgs.). Por uma análise automática do discurso. Campinas: Ed. da UNICAMP, 2010. pp. 159-249.

GADET, F.; PÊCHEUX, M. A Língua inatingível. O discurso na história da linguística. Campinas: Pontes, 2004.

HERBERT, Thomas. (PÊCHEUX, M.) Observações para uma teoria geral das ideologias. RUA, 1, Campinas, Unicamp, p. 63-89, 1995.

LATOUR, B.; JENSEN, P.; VENTURINI, T. et al. O todo é sempre menor que as partes: um teste digital acerca das mônadas de Gabriel Tarde [Trad. Bras.]. Parágrafo, v. 2, n. 3 jul. - dez. 2015.

MALINI, F. Um método perspectivista de análise de redes sociais: cartografando topologias e temporalidades em rede. Trabalho apresentado ao Grupo de Trabalho Comunicação e Cibercutura do XXV Encontro Anual da Compós, na Universidade Federal de Goiás, Goiânia, de 7 a 10 de junho de 2016. Disponível em http://fabiomalini.com/. Acesso em: 11. Jul. 2017.

PÊCHEUX, M. Análise de discurso e informática. Em: ORLANDI, Eni (Org.). Análise de Discurso Michel Pêcheux. Campinas, SP: Pontes Editores, 2014. pp. 275-282. 
PÊCHEUX, M. Ler o arquivo hoje. Em: ORLANDI, E. (Org.). Gestos de leitura: da história no discurso. Campinas: Pontes, 2010. pp. 49-59.

Só há causa daquilo que falha ou o inverno francês: início de uma retificação. Semântica e discurso. Uma crítica à afirmação do óbvio. Campinas: Ed. da Unicamp, 2009. pp. 269-281.

et al. Apresentação da análise automática do discurso (1982). Em: GADET, F.; HAK, T. (Org.). Por uma análise automática do discurso. Campinas: Ed. da UNICAMP, 2010. pp. 251-279.

et al. Présentation de l'analyse automatique du discours (AAD69): théories, procédures, résultats, perspectives. Mots, v. 4, n. 1, pp. 95-123, 1982. Disponível em http://www.persee.fr/doc/mots_0243-6450_1982_num_4_1_1053. Acesso em 18. jul. 2017.

O discurso: estrutura ou acontecimento. $5^{\mathrm{a}}$. ed. Campinas: Pontes Editores, 2008.

ORENSTEIN, J. Como combinar vinho com queijo, segundo o mapa interativo de um cientista canadense. Nexo Jornal, 14 abr. 2017. Disponível em https://www.nexojornal.com.br/expresso/2017/04/14/Como-combinar-vinho-comqueijo-segundo-o-mapa-interativo-de-um-cientista-canadense. Acesso: 19.jul. 2017.

ORLANDI, E. Discurso em Análise: sujeito, sentido, ideologia. Campinas: Pontes, 2012.

A contrapelo: incursão teórica na tecnologia - discurso eletrônico, escola, cidade. Rua [on-line], 2010. Disponível em http://www.labeurb.unicamp.br/rua/pages/home/capaArtigo.rua?id=91. Acesso em: 6 set. 2015.

. Discurso e leitura. São Paulo: Cortez, 2008.

Introdução às Ciências da Linguagem: discurso e textualidade. Campinas: Pontes, 2006. p. 13-31.

. Análise do discurso: princípios e procedimentos. 5ª ed. Campinas: Pontes, 2005.

Interpretação: autoria, leitura e efeitos do trabalho simbólico. Petrópolis, RJ: Editora Vozes, 1996.

PAVEAU, M.-A. L'intégrité des corpus natifs em ligne. Une écologie postdualiste pour la théorie du discours. Les cahiers de praxématique, Corpus sensibles, Montpellier, Presses Universitaires de la Méditerranée, 65-90, 2006-2015.

ŽIŽEK, S. Elementos para uma crítica do "novo materialismo". Ou, mais além de Latour, de volta a Hegel. Grupo de Estudos e Rede de Antropologia Crítica. Postado em 29 mar. 2017. Disponível em: https://antropologiacritica.wordpress.com/2017/03/29/elementospara-uma-critica-do-novo-materialismo-ou-mais-alem-de-latour-de-volta-ahegel/?blogsub=subscribed\#subscribe-blog. Acesso em 19.jul. 2017. 
Artigo recebido em: julho de 2017.

Aprovado e revisado em: outubro de 2017.

Publicado em: novembro de 2017.

\section{Para citar este texto:}

ALVES, Mariana Garcia de Castro. Grafos na leitura de AD. Entremeios [Revista de Estudos do Discurso, on-line, www.entremeios.inf.br], Seção Estudos, Programa de PósGraduação em Ciências da Linguagem (PPGCL), Universidade do Vale do Sapucaí (UNIVÁS), Pouso Alegre (MG), vol. 15, p. 109-126, jul. - dez. 2017.

DOI: http://dx.doi.org/10.20337/ISSN2179-3514revistaENTREMEIOSvol15pagina109a126 